\title{
Tissue plasminogen activator (alteplase) treatment for femoral artery thrombosis after cardiac catheterisation in infants and children
}

Werner Zenz, Wolfgang Muntean, Albrecht Beitzke, Gerfried Zobel, Michael Riccabona, Andreas Gamillscheg

\begin{abstract}
Objective-To determine the efficacy of fibrinolytic therapy with tissue plasminogen activator (alteplase) in infants and children with arterial thrombosis after cardiac catheterisation.

Design-Use of alteplase (Actilyse) in a protocol with prospective data collection. Alteplase was administered to infants and children with arterial thrombosis after cardiac catheterisation. A dose of $0.5 \mathrm{mg} / \mathrm{kg} / \mathrm{h}$ was given continuously via a peripheral vein for the first hour followed by $0.25 \mathrm{mg} / \mathrm{kg} / \mathrm{h}$ till clot lysis occurred or treatment had to be stopped because of bleeding complications.

Setting-University hospital, intensive care unit.

Patients-17 consecutive infants and children with femoral artery thrombosis after cardiac catheterisation between 1 April 1988 and 31 October 1991.

Main outcome measure-Reopening of the vessel.

Results-Complete clot lysis was achieved in 16 of 17 patients within 4-11 hours after the start of treatment. In one patient only partial lysis occurred. After complete lysis rethrombosis developed in one patient 15 hours after the end of treatment. Bleeding complications were seen in nine patients. These were restricted to the arterial puncture site, except for one who showed mild epistaxis. Three patients had to be treated with packed erythrocytes.
\end{abstract}

Clinical data
Department of Paediatrics, University of Graz, Austria

W Zenz

W Muntean

G Zobel

M Riccabona

Department of Paediatric Cardiology,

University of Graz,

Austria

A Beitzke

A Gamillscheg

Correspondence to:

Dr Werner Zenz

Universitäts Kinderklinik

Graz, Auenbruggerplatz 30

Accepted for publication

5 May 1993
A-8036 Graz, Austria.
Conclusions-Alteplase was an effective treatment of arterial thrombosis after cardiac catheterisation in infants and children. Further studies are needed to determine whether lower doses will reduce the frequently observed bleeding complications.

\section{(Br Heart F 1993;70:382-385)}

Femoral artery thrombosis is a common complication of retrograde arterial cardiac catheterisation in infants and children. ${ }^{1-5}$ Though severe tissue ischaemia causing amputation of the affected leg is rare, impairment of the growth and function of the leg can become severe, suggesting that treatment of femoral artery thrombosis is mandatory in this age group..$^{6-8}$

Surgical thrombectomy has been performed with varying success in children. ${ }^{8-10}$ Because the risk of extending vascular damage is high in neonates and infants, results may be poor in this age group. ${ }^{112}$ Thrombolytic agents offer an alternative to surgical treatment, but there are only a few reports of the use of streptokinase or urokinase as a thrombolytic agent in infants and children. ${ }^{69111314}$ Tissue plasminogen activator (alteplase) is a promising new fibrinolytic agent with several advantages over streptokinase and urokinase. ${ }^{15}$ So far there is little experience with this substance in infants and children. ${ }^{16-21}$ We describe the use of alteplase in 17 infants and children with femoral artery thrombosis after cardiac catheterisation.
"Unless stated otherwise. ${ }^{\star}$ Clot lysis: $+=$ complete clot dissolution; $\pm=$ partial clot dissolution; $(r)=$ rethrombosis. AVC, complete atrioventricular canal; AST, valvar aortic stenosis; COA, coarctation of the aorta; C-RV-F, coronary-right ventricular fistulas; DII, balloon dilatation; DORV, double outlet right ventricle; IAA, interrupted aortic arch; L-TGA, corrected transposition of the great arteries; MA, mitral atresia; PA, pulmonary atresia; PAB, pulmonary artery banding; PST, valvar pulmonary stenosis; TA, tricuspid atresia; TOF, tetralogy of Fallot; TGA, transposition of the great arteries; TAPVR, total anomalous pulmonary venous return; UVH, univentricular heart; VSD, ventricular septal defect. 


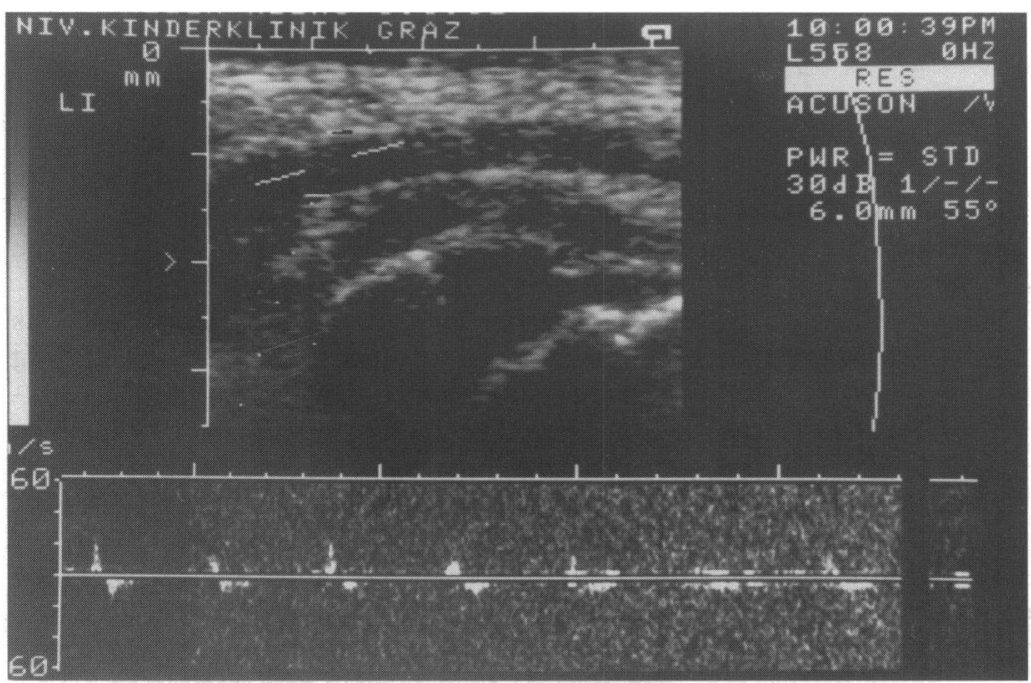

Figure 1 Cross sectional and $M$ mode echocardiograms of the left femoral iliac artery ( $5 \mathrm{MHz}$, linear transducer) of patient 16 (table) 18 hours after cardiac catheterisation showing hazy intraluminal echoes in the vessel. The Doppler gate $\left(a=55^{\circ}\right)$ was correctly positioned but no proper signals could be obtained. This indicated thrombosis.

\section{Patients and methods PATIENTS}

Between 1 April 1988 and 31 October 1991 we treated 17 consecutive patients $(13$ males, four females; aged 2 days to 7 years 5 months (mean 22 months) with congenital heart disease who had developed arterial thrombosis after retrograde cardiac catheterisation. Their weights ranged from $3 \mathrm{~kg}$ to $20 \mathrm{~kg}$ (mean $9.7 \mathrm{~kg}$ ). Arterial thrombosis had developed after selective retrograde catheterisation of the left ventricle in 14 and after balloon dilatation of valvar aortic stenosis or aortic coarctation in three patients (table).

HEPARIN THERAPY AND ALTEPLASE REGIMEN All patients were given an intravenous bolus of $100 \mathrm{U} / \mathrm{kg}$ heparin after arterial puncture. A continuous infusion of heparin (300 $\mathrm{U} / \mathrm{kg} /$ day) was given if arterial pulsation became reduced or disappeared, if blood

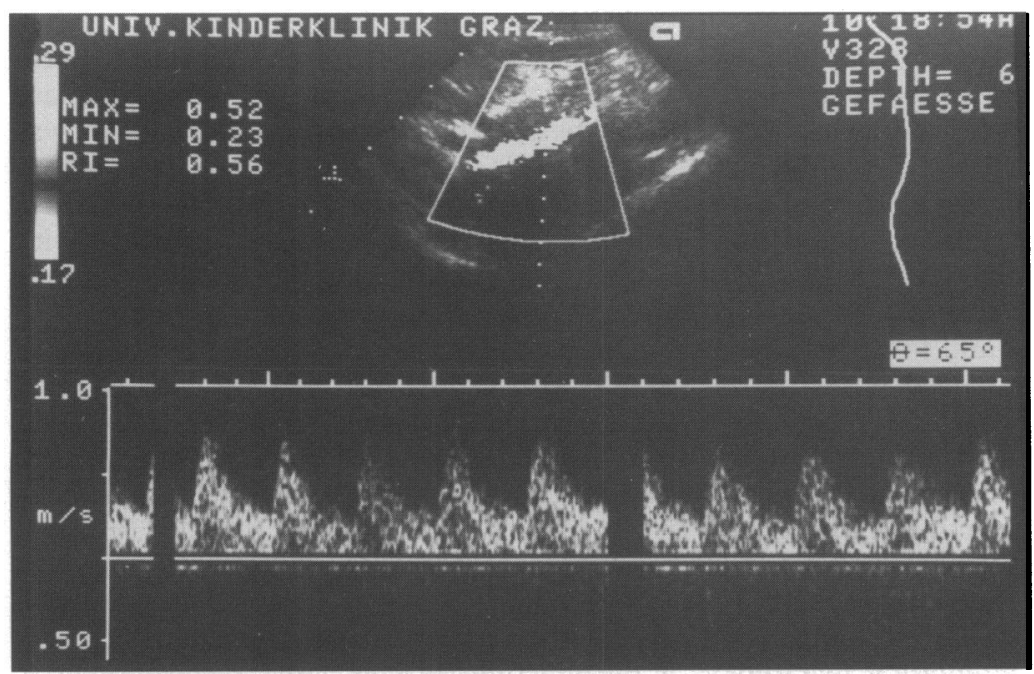

Figure 2 Black and white version of colour-coded Doppler echocardiogram of the left femoral iliac artery ( $3 \mathrm{MHz}$, sector transducer) in patient 16 (table) 10 hours after treatment with alteplase was started. The vessel was well perfused and a Doppler gated image $\left(a=65^{\circ}\right)$ showed flow that indicated recanalisation. pressure fell, or if pallor or reduced skin temperature developed in the cannulated leg. Femoral arterial thrombosis was diagnosed, if after 24 hours of heparin therapy the leg was still pulseless, blood pressure was low or unrecordable, and if there was poor skin perfusion and pallor compared with the other leg. Absence of pulses was confirmed by Doppler ultrasonography. In most patients arterial thrombosis was confirmed by colour coded Doppler sonography (Acuson $128 \mathrm{XP}$ 10 , 3-7 MHz transducer) (fig 1).

After 24 hours heparin was stopped and alteplase (Actilyse) was infused at a rate of $0.5 \mathrm{mg} / \mathrm{kg} / \mathrm{h}$ for the first hour followed by $0.25 \mathrm{mg} / \mathrm{kg} / \mathrm{h}$ until pulses were palpable and blood pressure in both legs was similar or bleeding complications occurred. Except for those cases with severe bleeding complications, the heparin infusion $(300 \mathrm{U} / \mathrm{kg} /$ day) was continued to 24 hours after alteplase treatment was stopped.

\section{LABORATORY TESTING}

Before treatment with alteplase was started a complete blood cell count was obtained and prothrombin time (PT) activated partial thromboplastin time (aPTT), thrombin time, fibrinogen, antithrombin III, liver enzymes (aspartate and alanine aminotransferases), urea, and creatinine were measured. Fibrinogen, thrombin time, PT, and aPTT were measured before, $2,4,8$, and $24 \mathrm{~h}$ after starting treatment with alteplase.

\section{Results}

Clot dissolution (fig 2) was complete in 16 patients. In one patient poor skin perfusion and pallor disappeared, posterior tibial pulses became palpable, and blood pressure in both legs was similar after six hours of alteplase treatment but the tibial pulses disappeared again 15 hours after alteplase was stopped. At thrombectomy a $10 \mathrm{~cm}$ long clot was recovered from the femoral artery of this patient. In one patient pulses reappeared and alteplase was stopped four hours after treatment started despite reduced blood pressure in the catheterised leg (table). This did not accord with the study protocol. This patient was discharged with partial clot dissolution and reduced blood pressure in the affected leg. Nine months later his pulses were normal and there was no blood pressure difference between the legs.

The mean duration of lysis was $7 \cdot 1$ (range 4-11 h). Eight patients bled from the arterial puncture site. In three bleeding was severe and they had to be treated with packed erythrocytes because of acute hypotension or a decrease of haematocrit of $>15 \%$ or both. In one of these three patients compression of the puncture site had been stopped too soon after the ultrasonographic examination. One patient showed mild epistaxis. No patient had a severe systemic bleeding diathesis or other side effects of alteplase treatment (table). The duration of treatment with alteplase was similar in patients with bleeding and in those 


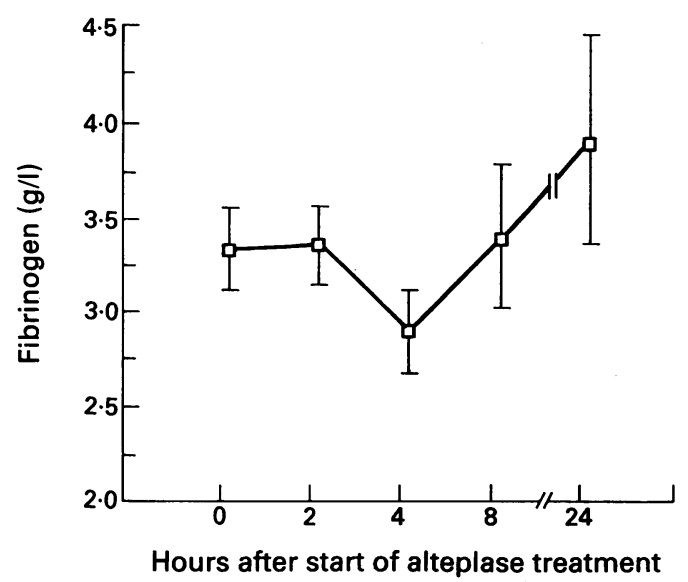

Figure 3 Mean (1 SD) fibrinogen and time after the start of alteplase treatment in 17 consecutive children with femoral artery thrombosis after cardiac catheterisation.

without, but bleeding was more common in older patients. The mean age of patients with bleeding was 26.9 months, whereas in patients without bleeding it was $16 \cdot 7$ months.

\section{LABORATORY DATA}

Fibrinogen concentrations remained constant during the first two hours of treatment and fell by a mean of $0.45 \mathrm{~g} / 1$ from the second to the fourth hour of treatment. By 24 hours after starting alteplase, fibrinogen concentrations had increased by a mean of $0.55 \mathrm{~g} / \mathrm{l}$ (fig 3). PT, aPTT, and thrombin times showed no clear trend.

Fibrinogen concentrations at the end of fibrinolytic treatment were known in seven patients without bleeding complications and in five patients with bleeding from the arterial puncture site. The mean fibrinogen concentration was $3.44 \mathrm{~g} / 1$ in the group without bleeding and $2 \cdot 15 \mathrm{~g} / \mathrm{l}$ in the group with bleeding. Fibrinogen concentrations at the end of fibrinolytic treatment had increased by 0.18 $\mathrm{g} / \mathrm{l}$ in the group without bleeding complications and decreased by $0.67 \mathrm{~g} / 1$ in the group with bleeding from the arterial puncture site.

\section{Discussion}

There are few reports on fibrinolytic therapy in childhood and most are of urokinase and streptokinase therapy. ${ }^{69111320}$ Alteplase has several advantages over these drugs-most importantly specific and strong binding to fibrin leading to preferential, efficient activation of fibrin-bound plasminogen. ${ }^{15}$ Though alteplase is a poor activator of circulating plasminogen, when it is bound to a fibrin surface it becomes several hundred times more effective. ${ }^{22}$ Fibrin-bound plasmin is stereochemically protected from the most potent plasmin inhibitor $a_{2}$-antiplasmin. ${ }^{15}$ Thus alteplase induces clot-selective fibrinolysis rather than the widespread proteolysis associated with activation of circulating plasminogen induced by streptokinase and urokinase. ${ }^{23}$

The plasma half life of alteplase is five minutes and is shorter than that of streptokinase and urokinase, allowing better dosage management. ${ }^{24}$ Because tissue plasminogen acti- vator is produced by human tissues as a therapeutic agent, alteplase, it is generally regarded as non-immunogenic. ${ }^{25}$

Experience with the use of alteplase in childhood, however, is limited and there are no prospective studies of its effects in thrombotic diseases in children and no clear dosage recommendations for this age group. ${ }^{16-21}$

In 16 of our 17 patients clot lysis was achieved with alteplase. In the remaining patient, who showed only partial clot dissolution, alteplase was stopped too soon. The duration of treatment ( $4 \mathrm{~h})$ was short compared with a mean lysis time of $7 \cdot 1$ hours for the whole group.

The frequency of rethrombosis was low and similar to other reports on streptokinase or urokinase in children with femoral artery thrombosis after cardiac catheterisation. ${ }^{6} 1314$

Bleeding complications were seen in nine patients (53\%), with bleeding and oozing from the arterial entry site, and all were controlled by groin compression. Bleeding always occurred when clinical signs of reperfusion of the leg appeared. Levy et al reported a similar high rate of bleeding complications in children when the dose of alteplase was $0.46-0.5$ $\mathrm{mg} / \mathrm{kg} / \mathrm{h} .^{16}$

Low concentrations of fibrinogen at the end of fibrinolytic treatment seemed to correlate with bleeding complications: mean fibrinogen was lower in patients with bleeding than in patients without. In patients with bleeding complications mean fibrinogen was lower at the end of lysis than before the start of alteplase treatment. In patients without bleeding complications the fibrinogen concentration remained constant. Close monitoring of fibrinogen during alteplase treatment may aid recognition of patients at an increased risk of bleeding complications. Bleeding and a decrease in fibrinogen did not seem to be correlated with duration of treatment, but bleeding was more common in older children. Bleeding complications may have been caused because the dose was adjusted for body weight in neonates, infants, and older children-hence a pharmacologically higher dose in older children.

The results of giving continuous heparin infusions during treatment with alteplase were better than when alteplase only was given. ${ }^{26} 27$ This suggests that treatment with a combination of alteplase and continuous heparin may achieve the same therapeutic effects with lower doses of alteplase, which might reduce the risk of bleeding complications.

But a trial of very low doses of alteplase in adults with venous thromboses did not yield good results. ${ }^{28}$ Children, however, usually do not show the same vascular risk factors for bleeding as adults and thus may tolerate relatively higher doses without bleeding. ${ }^{28}$ Much lower doses of alteplase have been used as local infusions but this approach is not to be practical in patients with arterial thrombosis at the puncture site after cardiac catheterisation. ${ }^{29}$

We conclude that alteplase was effective in inducing clot lysis in children with arterial thrombosis after cardiac catheterisation. 
Because bleeding complications were common, however, further studies with lower doses of alteplase in combination with heparin and doses adjusted for age will be required.

1 Stanger $P$, Heymann MA, Tarnoff $H$, Hoffman JIE, Rudolph AM. Complications of cardiac catheterization of neonates, infants and children. A three-year study. of neonates, infants and ch

2 Perry SB, Keane JF, Lock JE. Interventional catheterization in pediatric congenital and acquired heart disease. Am $\mathcal{f}$ Cardiol 1988;61:109G-17.

3 Beitzke A, Mache CJ, Stein JI, Suppan C. Komplikationen bei zwei Serien von je 1000 Herzkatheteruntersuchungen im Kindesalter. Wien Klin Wochenschr 1991;103:75-81.

4 Girod DA, Hurwitz RA, Caldwell RL. Heparinization for prevention of thrombosis following pediatric percutaneous arterial catheterization. Pediatr Cardiol 1982; 3:175-80.

5 Freed MD, Keane JF, Rosenthal A. The use of heparinization to prevent arterial thrombosis after per-
cutaneous cardiac catheterization in children. Circulation 1974;50:565-9.

6 Wessel DL, Keane JF, Fellows KE, Robichaud H, Lock JE. Fibrinolytic therapy for femoral arterial thrombosis after cardiac catheterization in infants and children. $\mathrm{Am}$ f Cardiol 1986;58:347-51.

7 Hurwitz RA, Franken EA, Girod DA, Smith JA, Smith WL. Angiographic determination of arterial patency after percutaneous catheterization in infants and small children. Circulation 1977;56:102-5.

8 White J, Talbert JL, Haller JA. Peripheral arterial injuries in infants and children. Ann Surg 1968;167:757-66.

9 Mansfield PB, Gazzaniga AB, Litwin SB. Management of arterial injuries related to cardiac catheterization in children and young adults. Circulation 1970;42:501-7.

10 Flanigan DP, Keifer TJ, Schuler JJ, Ryan TJ, Castronuovo J. Experience with iatrogenic pediatric vascular injuries: Jn. Experience with iatrogenic pediatric vascular injuries: Incidence, etiology,

11 Burrows PE, Benson LN, Williams WG, et al. Iliofemoral arterial complications of balloon angioplasty for systemic obstructions in infants and children. Circulation 1990;82:1697-1704.

12 Leblanc J, Wood AE, O'Shea MA, et al. Peripheral arterial trauma in children: A fifteen year review. $\mathcal{f}$ Cardiovasc Surg 1985;26:325-31.

13 Ino T, Benson LN, Freedman RM, et al. Thrombolytic diac catheterization. Am Heart $\mathcal{F}$ 1988;115:633-9.
14 Brus F, Witsenburg M, Hofhuis WJD, Hazelzet JA, Hess J. Streptokinase treatment for femoral artery thrombosis after arterial cardiac catheterisation in infants and children. Br Heart F 1990;63:291-4.

15 Collen $D$. On the regulation and control of fibrinolysis. Thromb Haemost 1980;43:77-89.

16 Levy M, Benson LN, Burrows PE, et al. Tissue plasminogen activator for the treatment of thromboembolism in infants and children. $\mathcal{F}$ Pediatr 1991;118:467-72.

17 Kennedy LA, Drummond WH, Knight ME, Millsaps MM, Williams JL. Successful treatment of neonatal aortic thrombosis with tissue plasminogen activator. $\mathcal{f}$ tic thrombosis with tissue

18 Pyles LA, Pierpont MEM, Steiner ME, Hesslein PS, Smith II CM. Fibrinolysis by tissue plasminogen activator in a child with pulmonary embolism. F Pediatr tor in a child wir

19 Kreuz W, Nowak-Göttl U, Schwabe D, Stöver B. Therapeutical aspects in arterial and venous thrombosis in children. Blut 1989;58:309.

20 Strife JL, Ball WS, Towbin R, Keller MS, Dillon T. Arterial occlusions in neonates: use of fibrinolytic therapy. Radiology 1988;166:395-400

21 Anderson BJ, Keeley SR, Johnson ND. Caval thrombolysis in neonates using low doses of recombinant human tissue-type plasminogen activator. Anaesth Intens Care
1991;19:22-7.

22 Marder VJ, Sherry S. Thrombolytic therapy: Current status (second of two parts). N Engl $\mathcal{f}$ Med 1988;318: 1585-95.

23 Collen D, Stump DC, Gold HK. Thrombolytic therapy. Ann Rev Med 1988;39:405-23.

24 Marder VJ, Sherry S. Thrombolytic therapy: Current status (first of two parts). N Engl $f$ Med 1988;318: 1512-9.

25 Levin EG. Latent tissue plasminogen activator produced by human endothelial cells in culture: evidence for an enzyme-inhibitor complex. Proc Natl Acad Sci USA 1983;80:6804-8.

26 Hsia J, Hamilton WP, Kleiman N, et al. A comparison between heparin and low-dose aspirin as adjunctive therapy with tissue plasminogen activator for acute myocardial infarction. N Engl IMed 1990;323:1433-7.

27 De Bono DP, Simoons ML, Tijssen J, et al. Effect of early intravenous heparin on coronary patency, infarct size, and bleeding complications after alteplase thrombolysis: results of a randomised double blind European Cooperative Study Group trial. Br Heart $f$ 1992;67: 122-8.

28 Bounameaux H, Banga JD, Bluhmki E, et al. Doubleblind, randomised comparison of systemic continuous infusion of 0.25 versus $0.50 \mathrm{mg} / \mathrm{kg} / 24 \mathrm{~h}$ of alteplase over 3 to 7 days for treatment of deep venous thrombosis in heparinized patients: results of the European thrombolysis with rt-PA in venous thrombosis (ETTT) trial. Thromb Haemost 1992;67:306-9.

29 Doyle E, Britto J, Freeman J, Munro F, Morton NS. Thrombolysis with low dose tissue plasminogen activator. Arch Dis Child 1992;67:1483-4. 